Portland State University

PDXScholar

\title{
Crystallographic Processing of Scanning Tunneling Microscopy Images of Cobalt Phthalocyanines on Silver and Graphite
}

\author{
Peter Moeck \\ Portland State University \\ Taylor T. Bilyeu \\ Portland State University \\ Jack C. Straton \\ Portland State University, straton@pdx.edu \\ $M$ Toader \\ Chemnitz University of Technology \\ M. Hietschold \\ Chemnitz University of Technology
}

Follow this and additional works at: https://pdxscholar.library.pdx.edu/phy_fac

Part of the Nanoscience and Nanotechnology Commons

Let us know how access to this document benefits you.

\begin{abstract}
Citation Details
Moeck, P., Straton, J., Toader, M., \& Hietschold, M. (2011). Crystallographic processing of scanning tunneling microscopy images of cobalt phthalocyanines on silver and graphite. MRS Online Proceedings Library Archive, 1318.
\end{abstract}

This Citation is brought to you for free and open access. It has been accepted for inclusion in Physics Faculty Publications and Presentations by an authorized administrator of PDXScholar. Please contact us if we can make this document more accessible: pdxscholar@pdx.edu. 


\title{
Crystallographic Processing of Scanning Tunneling Microscopy Images of Cobalt Phthalocyanines on Silver and Graphite
}

\author{
P. Moeck*e, T. T. Bilyeu*, J. C. Straton*, M. Toader**, and M. Hietschold** \\ *Nano-Crystallography Group, Department of Physics, Portland State University, Portland, OR \\ 97207-075 e pmoeck@pdx.edu \\ ** Institute of Physics, Chemnitz University of Technology, D-09126 Chemnitz, Germany
}

Monolayers of cobalt phthalocyanine ( $\mathrm{CoPc})$ on silver (111) and highly (0001) oriented pyrolytic graphite (HOPG) were imaged with a scanning tunneling microscope (STM) at cryogenic temperatures (around $30 \mathrm{~K}$ ) at Chemnitz University of Technology, Figs. 1a and 2a. Domains of regular arrays with periodicity in two dimensions (2D) and a variety of plane symmetries [1] were observed.

Crystallographic image processing (CIP) [2] was used to quantify deviations from the plane symmetry groups and to obtain symmetrized versions of the content of the average unit cells of these arrays, Figs. 1b,c and 2b-e. While classical Fourier filtering may be considered to be the simplest form of CIP (Figs. 1c, 2c,e), our full utilization of CIP also delivers the symmetry averaged periodic motif as well as information on the point symmetry of molecules in regular 2D periodic arrays [3]. Supported by the experimental data of ref. [4], we speculate on the basis of our CIP results that the CoPc molecules are inclined relative to the HOPG substrate at cryogenic temperatures [3].

Although only demonstrated for STM images in this paper, CIP is applicable to all kinds of scanning probe microscopy (SPM) images of 2D periodic arrays. A dedicated computer program for CIP of SPM images is under development, see Fig. 3. This program will allow for the extraction of the point spread function of a SPM from an image of a highly symmetric calibration sample and the usage of this function for the correction of subsequently recorded SPM images. Also, we will utilize geometric Akaike criteria [5] for decisions on which plane group an experimental SPM image most likely possesses. The first author of this paper asks the scientific community to send him raw images of $2 \mathrm{D}$ periodic arrays so that he can demonstrate the benefits of CIP to a wider audience (in future joint publications) [6].

\section{References}

[1] T. Hahn (editor), International Tables for Crystallography. Brief Teaching Edition of Volume A, Space-group Symmetry, $5^{\text {th }}$ rev. ed., Chester, International Union of Crystallography, 2005.

[2] P. Moeck, in: Microscopy: Science Technology, Applications and Education, Microscopy Book Series, Vol. 4, A. Méndez-Vilas and J. Diaz eds., 2011, http://www.formatex.org/microscopy4/.

[3] P. Moeck, J. Straton, M. Toader, M. Hietschold, Proc. Fall 2010 Meeting of the Materials Research Society, http://journals.cambridge.org/action/displayJournal?jid=OPL

[4] T. Kataoka, H. Fukagawa, S. Hosoumi, K. Nebashi. K. Sakamoto, and N. Ueno, Chem. Phys. Lett. 451 (2008) 43.

[5] K. Kanatani, Inter. J. of Computer Vision 26 (1998) 171.

[6] Portland State University (PSU) supported this work with Research Stimulus, Faculty Enhancement, and Internationalization Awards. PSU's Venture Fund supported the initial stage of the development of our dedicated CIP software for SPM imaging. The experimental work at Chemnitz University of Technology was supported by the Deutsche Forschungsgemeinschaft. 

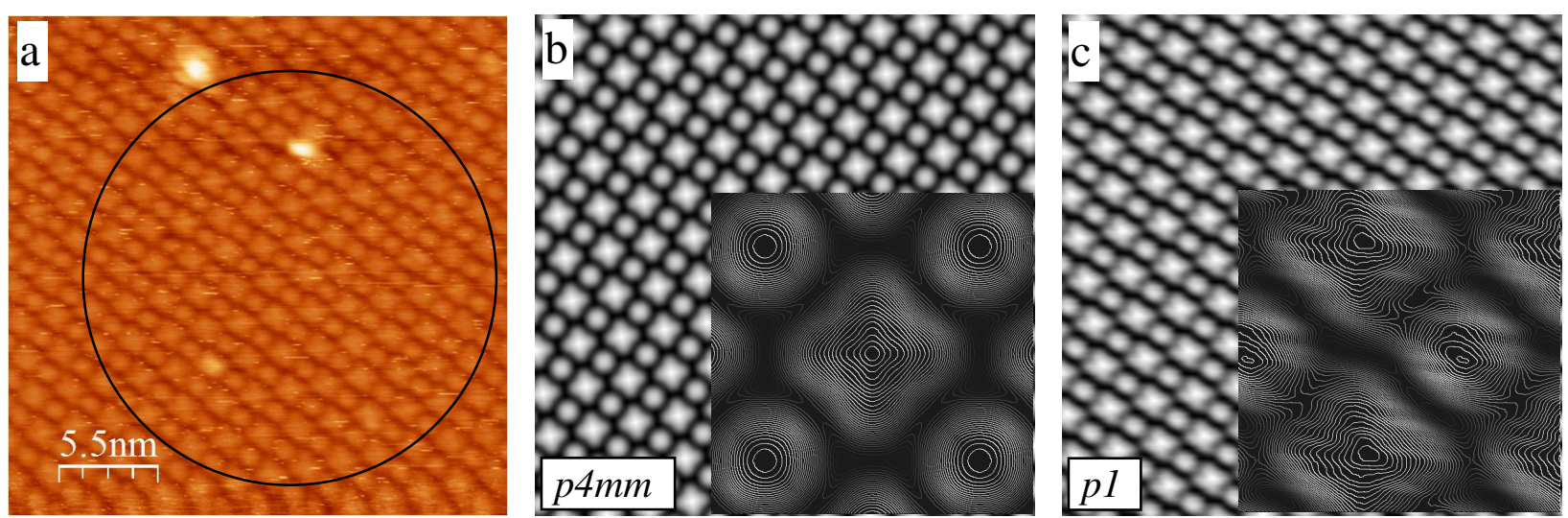

FIG. 1. CoPc on $\mathrm{Ag}(111), \mathrm{I}_{\mathrm{T}}=150 \mathrm{pA}, \mathrm{U}_{\mathrm{T}}=-1.0 \mathrm{~V}$; (a) Raw STM data with selection for the application of the CIP procedures; (b) $p 4 m m$ enforced version of this data (on the basis of a circular selection of 512 pixels diameter, which contained about 90 periodic motifs) with a quadratic unit cell inset as contour plot; and (c) translation averaged ( $p 1$ enforced, i.e. classical Fourier filtered) version of the data (on the same basis) with an oblique unit cell inset as contour plot. For convenience, the contour plot insets were rotated clockwise by approximately $8^{\circ}$.
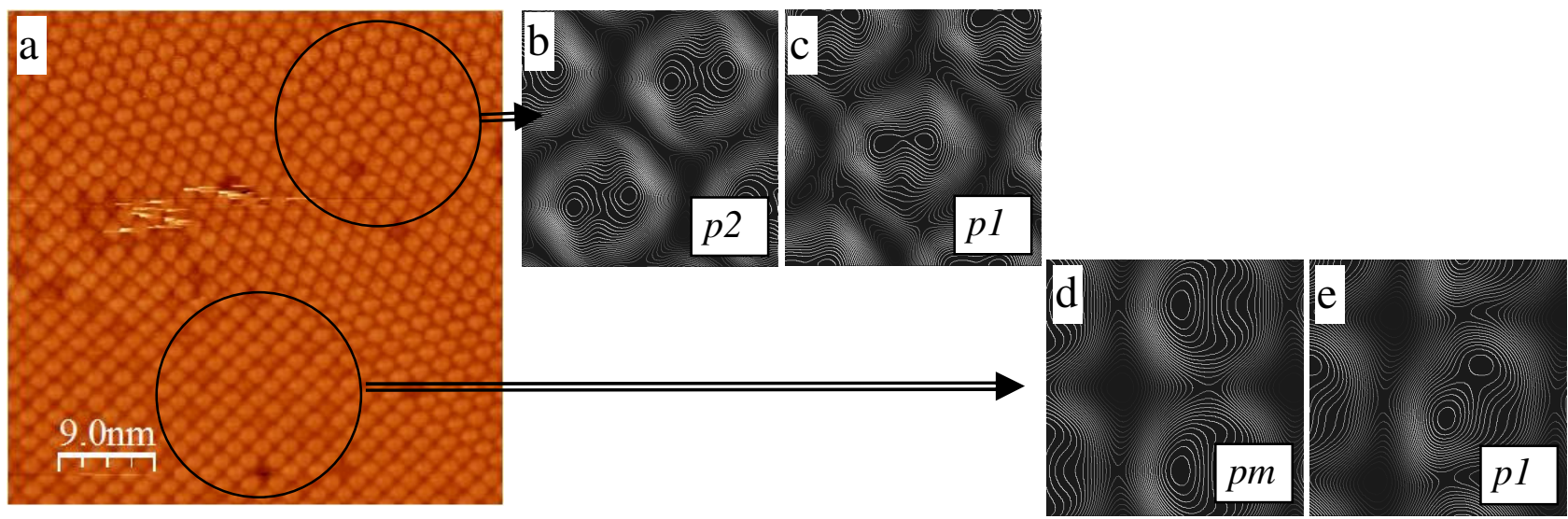

FIG. 2. CoPc on HOPG, $\mathrm{I}_{\mathrm{T}}=80 \mathrm{pA}, \mathrm{U}_{\mathrm{T}}=+1.0 \mathrm{~V}$; (a) Raw $\mathrm{STM}$ data with two domains and selections for the application of the CIP procedures; (b) $p 2$ enforced motif as contour plot for the selected data from the upper domain (on the basis of the upper circular selection with a diameter of 126 pixels, which contains about 85 periodic motifs); (c) translation averaged motif as contour plot for the same data (from the upper domain); (d) pm enforced motif as contour plot for the selected data from the lower domain (on the basis of the lower circular selection with a diameter of 126 pixels, which contains about 90 periodic motifs); and (e) translation averaged motif as contour plot for the same data (from the lower domain).

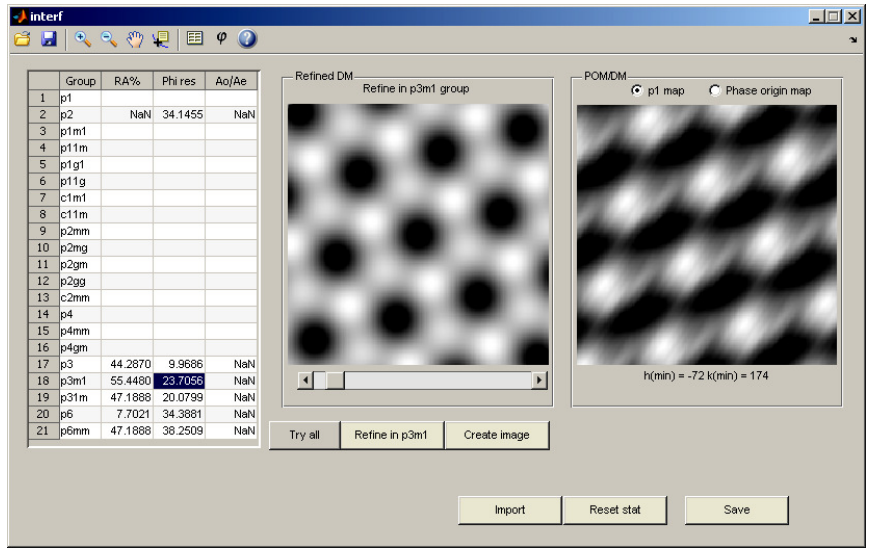

FIG 3. Screenshot of one of the interactive windows of PSU's CIP program for SPM. The right panel shows translation averaged STM data of a regular 2D periodic array of fluorinated $\mathrm{CoPc}$ molecules on HOPG. For illustrative purposes, the middle panel shows this data symmetrized to the plane group of HOPG. This group could be a supergroup of the molecular array. We assume that the molecules are arranged in the $c 1 \mathrm{ml}$ subgroup of this plane group and are not lying flat on the substrate [3]. We are in the process of utilizing geometric Akaike criteria [5] to test this hypothesis. 